\title{
Integrating Congestion Pricing and Transit Investment Planning
}

\author{
A Thesis \\ Presented to the Faculty of the Graduate School \\ of Cornell University \\ In Partial Fulfillment of the Requirements for the Degree of \\ Master of Science
}

by

Ruoyun Chen

August 2015 
(C) 2015 Ruoyun Chen 


\begin{abstract}
This paper develops a mathematical model and solution procedure to identify an optimal zonal pricing scheme for automobile traffic to incentivize the expanded use of transit as a mechanism to stem congestion and the social costs that arise from that congestion. The optimization model assumes that there is a homogenous collection of users whose behavior can be described as utility maximizers and for which their utility function is driven by monetary costs. These monetary costs are assumed to be the tolls in place, the per mile cost to drive, and the value of their time. We assume that there is a system owner who sets the toll prices, collects the proceeds from the tolls, and invests those funds in transit system improvements in the form of headway reductions. This yields a bi-level optimization model which we solve using an iterative procedure that is an integration of a genetic algorithm and the Frank-Wolfe method. The method and solution procedure is applied to an illustrative example.
\end{abstract}




\section{BIOGRAPHICAL SKETCH}

Ruoyun Chen was born in China in April 23 ${ }^{\text {rd }}$ 1991. She lived in Beijing for 18 years until she finished her high school in Affiliated High School of Peking University. She then went to Nanjing, Jiang Su Providence for her undergrad at Southeast University, where her major is Transportation Engineering. In the year 2013, she received her Bachelor of Engineering degree from Southeast University. Later that year, she went to Cornell University for her Master education. At Cornell, she major in Transportation System Engineering in the Department of Civil and Environment Engineering. The chair of her graduate special committee is Professor Linda K. Nozick, and her minor advisor is Jon Kleinberg. Her research interests are Network Game, Pricing Mechanism and Alleviating Traffic Congestion. She has her Master Thesis Defense on July $31^{\text {st }}, 2015$. 


\section{ACKNOWLEDGMENTS}

I want to first give my sincere appreciation to Professor Linda K. Nozick, who is my major advisor and the chair of my graduate special committee. I want to thank her for five reasons: First, for encouraging me to integrate my interest in network science and game theory with transportation research; second, for being so accessible when I need to discuss theory and methodology with her, whenever and wherever she is; third, for being so generous when giving me suggestion not only on how to do research, but also on how to present my idea accurately and elegantly; fourth, for being so supportive when I want to test new ideas even when it's getting very close to the end; fifth, for constantly giving me feedback and showing her confidence in me. She is the one who make everything happens. She let me become the person I always want to be. She is my lifetime mentor.

I shall extend my thanks to Professor Jon Kleinberg, who is my minor advisor. I was not aware of the area of information science and network science before I went to Cornell. It is his course Network that let me know this incredible and emerging field. I found my passion through his research, his paper, his book, his lecture and his talk. He inspires me so many times in so many ways.

My appreciation also goes to Professor David Easley, Professor Huseyin Topaloglu, Professor Christine Shoemaker, Professor Steve Strogatz, and Professor Steven Jackson. They are all brilliant Professors who not only give fascinating lectures but also really want their student to enjoy the beauty of research. They make Cornell's history and future.

Finally, I want to give my deepest appreciation to my parents and my beloved husband Shuo Yan for their endless love and support. Shuo is my emotion manager and the art 
consultant of my thesis. He filled this process with full of surprises and fun. He is my lifetime soulmate and partner. Happy three-year-anniversary to us. 


\section{TABLE OF CONTENTS}

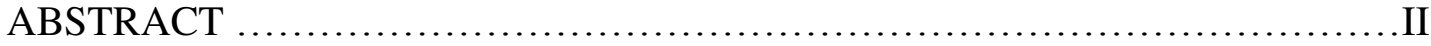

ACKNOWLEDGMENT ..................................................IV

TABLE OF CONTENTS $\ldots \ldots \ldots \ldots \ldots \ldots \ldots \ldots \ldots \ldots \ldots \ldots \ldots \ldots \ldots \ldots \ldots \ldots \ldots . . \ldots \ldots \ldots$

Chapter 1. Introduction................................................ 1

Chapter 2. Literature Review..............................................2

Chapter 3. Formulation....................................................

3.1 Mode and Arc Assignment.............................................. 5

3.2 Optimization for Systems Owner........................................ 7

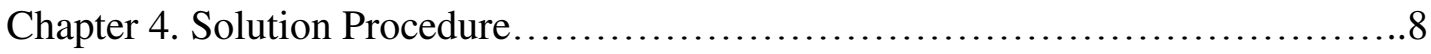

Chapter 5. Illustrative Case Study........................................ 9

5.1 Road Network......................................................... 9

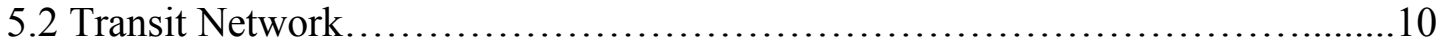

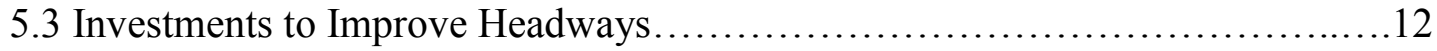

5.4 Illustrative results....................................................... 14

Chapter 6. Conclusions and Next Steps...................................20

Reference................................................................. 21

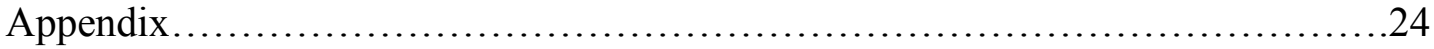




\subsection{Introduction}

Congestion was estimated to cost on the order of $\$ 124$ billion in 2013 and is projected to rise to about $\$ 186$ billion by 2030 (Forbes, 2014). The Texas Transportation Institute estimates that (TTI, 2012) in 2011 urban Americans traveled about 5.5 billion additional hours and purchased an extra 2.9 billion gallons of fuel as a result of congestion. They also estimate that travelers in congested areas needed to set out an hour earlier for a trip that should have taken only 20 minutes in free flow traffic conditions. While freeway incident management, freeway ramp metering, arterial street signal coordination, arterial street access management and high-occupancy vehicle lanes are estimated to save 374 million hours of travel delay and $\$ 8.5$ billion of congestion cost, public transportation is estimated to save about 865 million hours of travel delay and $\$ 20.8$ billion in congestion costs. It is the opportunity to more fully exploit the benefits of public transportation that motivates this research.

One mechanism to spur the use of public transportation is to increase automotive costs through congestion pricing. Congestion pricing schemes often face political opposition. In 2008 New York City abandoned congestion pricing efforts for Manhattan (The New York Times, 2008). Similar proposals have been abandoned in Greater Manchester, UK, Hong Kong, China, for example. Some congestion pricing schemes have been implemented however; including Stockholm, London and Singapore as well as Orange County in California, and San Diego in the United States.

An important characteristic in assessing the likelihood of adoption of a congestion pricing scheme is the perceived equity in that scheme. Volpe and the U.S. DOT report (Rand Corp and Volpe National Transportation Systems Center, 2007) that travelers in the more busy direction during rush hour under congestion pricing schemes are wealthier. Further, when only some lanes are priced, they indicate that on average, wealthier drivers make use of the priced lanes. One mechanism to offset the equity challenges associated with congestion pricing is to make use of the revenues generated to 
improve the transportation options of lower income groups. It is this very strategy that is behind the requirement that $18 \%$ of the funds generated from congestion pricing in the San Francisco Bay Area (DOT, 2008) be used to subsidize bus transportation. Similarly, some of the proceeds from the London congestion fee are earmarked for investment in public transit services. Those proceeds amounted to about $£ 1.2$ billion over the first 10 years in which the pricing scheme was in effect (Lydall, 2013).

Given the opportunity to stem congestion via congestion pricing, the criticality of controlling inequity in the pricing scheme developed as well as the demonstrated benefit of public transportation to control congestion, we focus on the development of a mathematical model to identify roadway prices and service improvements in an associated transit system so as to maximize the social welfare of the population.

The remainder of this paper is organized into five sections. Section 2 presents relevant literature. Section 3 formulates the bi-level optimization model. The upper level model focuses on establishing the prices and the use of those funds to improve transit services. The lower level is a traffic assignment model over the highway and transit networks. Section 4 gives the solution procedure to the formulation given in Section 3. Finally Section 5 gives an illustrative example. Section 6 gives conclusions and opportunities for future research.

\subsection{Literature Review}

There is a large theoretical and empirical literature focused on congestion pricing. For a comprehensive literature review see Liu (2011). First-best pricing, also known as marginal cost pricing, is to set toll fees equal to the negative congestion externality users impose to each other (Walters, 1961; Yang et al., 1998; Verhoef et al., 2008). However, the first-best pricing scheme requires that charges are assigned to every link in the network so as to achieve the system optimum 
solution. Practical considerations often make this approach impossible to implement. Allowing only a proportion of links to be charged, known as the second-best pricing scheme was first proposed by Marchand (1968).

The second-best pricing problem is formulated as a hierarchical network game (Shimizu et al., 1997; Bard, 1998) with a single network owner looking for prices to minimize the total travel time where a large number of competing users choose paths by optimizing over toll fees and travel cost. This is essentially a Stackelberg game (Basar et al., 1998), and can be expressed as a mathematical programming model with equilibrium constraints (MPEC) (Luo et al., 1996). This basic structure has been extended in several important ways including heterogeneous users (Cole et al., 2003), and stochastic demands (Liu, 2011). Bergendorff, Hearn and Ramana (Hearn et al, 1998) allow link tolls to be positive or negative, with negative tolls indicating a subsidy is warranted for travel on those links. Conceptually, this is similar to using toll revenues raised to subsidize other users, including those making use of transit.

Parry and Bento (1999) made the suggestion to reduce labor taxes through congestion tax revenue to offset the negative effects on the labor force caused by the congestion pricing scheme. Similarly, Small (Small, 1992) designed a package of expenditures that would use one-third of congestion pricing revenues to improve the transportation system in the congested area, and returns the remainder of the funds to travelers via tax reductions and access allowances (e.g. program of employee commuting allowances).

Regarding to the concept of cross-subsidization as discussed in Bergendorff, Hearn and Ramana, Fielding (1995) argues that non-peak period commuters have already cross-subsidized peak users because it is the peak users that create the need for additional lanes (and therefor higher charges). Hence one could argue that charges should be levied against the users in congested periods to cross-subsidize disadvantaged users who are forced to choose alternatives modes. Other authors 
including Litman (1996) examined the economic efficiency, equity, and political feasibility of aspects of congestion pricing and claimed that road pricing revenue should be used to benefit low-income drivers and non-drivers. Other papers in this same vein include Goodwin (1989), Poole (1992), Bernstein (1993), Arnott et al. (1994) DeCorla-Souza (1995), Adler and Cetin (2001), Eliasson (2001) and Kalmanje and Kockelman (2004).

Based on these arguments, we focus on optimizing both the pricing scheme and the use of the resultant funds to cross-subsidize public transportation. This paper, to the authors' knowledge, is the first paper to jointly optimize road toll prices and investments in a related mode of transportation, transit. Yang et al. (2004), Nie et al. (2009), and Liu et al. (2009) all consider road and transit networks simultaneously but their focus is on the return of congestion pricing funds to the transit ridership via transit fee refunds or direct fare reductions whereas our is on improving the quality of transit services.

\subsection{Formulation}

This section develops a bi-level optimization model to optimize zonal prices for automobiles in an urban transportation network where there is the opportunity to substitute transit for automotive trips. We assume that individual travelers select the mode and path using a network $(N, A)$ where $N$ is the set of nodes and $A$ is the set of arcs in the network, which maximizes their utility. We assume that the system owner wants to maximize the social welfare of the individuals making use of the facilities. They do this by making use of a zonal pricing scheme for automobiles which gives prices for automobiles to make use of specific links in the network. The funds raised from these tolls are assumed to be invested in the transit system to reduce the headways thereby reduce travel times in the transit system.

The remainder of this section gives the resultant bi-level optimization problem. The first subsection gives the network assignment model given fixed prices on each of the arcs (which is a user 
equilibrium model with variable demand as given in Sheffi (1985)). This is the lower level model. The second subsection gives the optimal pricing problem for the system owner. This is the upper level problem.

\subsection{Mode and Arc Assignment}

We assume that the utility for transit verses automobile is a function of difference in the monetary costs between the modes in addition to other individual preferences which are not directly observable, quantifiable or measureable. To address the inadequacies in the data available to estimate the utility function, we assume that given the monetary costs of each of the modes for each origin-destination pair, the logit function can be used to estimate the mode split.

The total cost of traveling as defined by Cesario (1976) is the sum of cost of travel time, cost of travel distance, and cost of visiting. We therefore correspondingly assume the monetary cost of using automobile is composed of three parts: monetary value of travel time, distance-based driving cost, and toll prices on selected arcs. Hence the monetary cost by adopting path $\mathrm{k}$ on road network is formulated as

$$
v u_{r s}^{k}+\sum_{a}\left[\left(p_{a}+c_{d} d_{a}\right) \delta_{a, k}^{r s}\right]
$$

where $u_{r s}^{k}$ is the travel time from $r$ to $s$ that use path $\mathrm{k}$ in the automobile network, $v$ is the value of time, $p_{a}$ is the toll price on $\operatorname{arc} a, c_{d}$ is the per mile driving cost, $d_{a}$ is the length of link a, and $\delta_{a k}^{r s}$ take on a value of one if $\operatorname{arc} a$ is on path $k$ from $r$ to $s$ and is zero otherwise.

Further, let's assume that the cost to take transit from origin $r$ to destination $s$, assuming the headways and in-vehicle travel times are fixed, are as given in equation (2)

$$
v \hat{u}_{r s}
$$

where $\hat{u}_{r s}$ is the travel time from origin $r$ to destination $s$ using transit where we assume that the transit travel time is the sum of in-vehicle travel time and waiting time. In a transit network where there are multiple routes that are available from $r$ to $s, \hat{u}_{r s}$ corresponds to the travel time of the route that has the shortest travel time. For the purposes of this analysis, we assume that travelers always wait half the headway for the transit vehicle to arrive and for each origin-destination pair 
they select the shortest path through the transit system and do not make use of any information that may become available as the transit trip unfolds. Notice that there is no fare to take transit in this formulation but it could be easily added if needed.

Assuming $c_{r s}$ is the monetary cost for the cheapest path from origin $r$ to destination $s$, which can be expressed as

$$
c_{r s}=\min _{k} v u_{r s}^{k}+\sum_{a}\left[\left(p_{a}+c_{d} d_{a}\right) \delta_{a, k}^{r s}\right]
$$

Hence the logit function adopted to estimate the automotive share is

$$
q_{r s}=\bar{q}_{r s} \frac{1}{1+e^{\varnothing\left(c_{r s}-v u_{r s}(H)\right)}}
$$

where $\bar{q}_{r s}$ is the total number of trips from origin $r$ to destination $s, q_{r s}$ is the number of trips from origin $\mathrm{r}$ to $\mathrm{s}$ by automobile, $\widehat{u_{r s}(H)}$ is the travel time via transit from origin $r$ to destination $s$, which is the function of transit headway, $H$, and $\emptyset$ is a population specific parameter.

Using equations (1) - (4), at optimality we can see that equation (4) must hold

$$
\begin{gathered}
\frac{\bar{q}_{r s}}{q_{r s}}=1+e^{\emptyset\left(c_{r s}-v \overline{u_{r s}(H)}\right)} \\
\frac{\bar{q}_{r s}-q_{r s}}{q_{r s}}=e^{\left.\emptyset\left(c_{r s}-v \widehat{u_{r s}(H}\right)\right)} \\
v \widehat{u_{r s}(H)}+\frac{1}{\phi} \ln \left(\frac{\bar{q}_{r s}-q_{r s}}{q_{r s}}\right)=c_{r s}
\end{gathered}
$$

Equation (5) implies that the monetary cost at optimality for the cheapest path from origin $r$ to destination $s$ in the automobile network must equal the cost in the transit plus this additional term, $\frac{1}{\varnothing} \ln \left(\frac{q_{r s}}{\bar{q}_{r s}-q_{r s}}\right)$. Hence we represent the transit choice between origin $r$ and destination $s$ as a directed link from node $r$ to node $s$ with the volume to delay curve given on the left-hand side of equation (5).

Let $\bar{A}$ be the set of arcs in the network that are part of the automobile network; hence $\bar{A} \subseteq A$. For each arc $\in \bar{A}$, we assume that the travel time takes the following form.

$$
t_{a}\left(1+\alpha_{a}\left(\frac{x_{a}}{c_{a}}\right)^{\beta_{a}}\right)
$$


where $t_{a}$ is the free flow time, $x_{a}$ is the volume on $\operatorname{arc} a, C_{a}$ is the capacity of arc a and $\alpha_{a}$ and $\beta_{a}$ are link specific parameters. Therefore, the cost to use automobile arc $a$ is as follows

$$
v t_{a}\left(1+\alpha_{a}\left(\frac{\omega}{c_{a}}\right)^{\beta_{a}}\right)+c_{d} d_{a}+p_{a}
$$

With this as preparation, the formulation of the equilibrium traffic assignment problem, where the toll prices, $p_{a}$, and the transit headways are fixed is as follows.

$\min \tilde{z}(x, \hat{q})=$

$$
\sum_{a \in \bar{A}} \int_{0}^{x_{a}}\left[v t_{a}\left(1+\alpha_{a}\left(\frac{\omega}{c_{a}}\right)^{\beta_{a}}\right)+p_{a}+c_{d} d_{a}\right] d \omega+\sum_{r s} \int_{0}^{\widehat{r_{r s}}}\left(\frac{1}{\theta} \ln \frac{\omega}{\bar{q}_{r s}-\omega}+v \widehat{u_{r s}(H)}\right) d \omega
$$

Subject to

$$
\begin{array}{cc}
\sum_{k} f_{k}^{r s}+\hat{q}_{r s}=\bar{q}_{r s} & \forall r, s, k \\
x_{a}=\sum_{r s k} f_{k}^{r s} \delta_{a k}^{r s} & \forall a \\
f_{k}^{r s} \geq 0 & \forall r, s, k \\
0<\hat{q}_{r s}<\bar{q}_{r s} & \forall r, s
\end{array}
$$

\subsection{Optimization for Systems Owner}

Next we formulate the system owner's optimization. We let $\hat{p}$ be a vector of the tolls prices, where $p_{a}$ is the toll instituted on $\operatorname{arc} a$; hence $\hat{p}=\left(p_{a}\right)$. Further we assume that the headways are a function of the toll revenue collected; hence the origin to destination travel times via transit are a function of the headways and therefore the toll revenue collected. This yields the following objective function for the system owner

$$
\min \sum_{a \in \bar{A}} x_{a}(\hat{p}) t_{a}\left(1+\alpha_{a}\left(\frac{x_{a}(\hat{p})}{C_{a}}\right)^{\beta_{a}}\right)+\sum_{r s} \hat{q}_{r s} \hat{u}_{r s}(H(\hat{p})) .
$$

The non-negativity restrictions on the prices must also be satisfied. That is equations (13) below must hold.

$$
p_{a} \geq 0 \quad \forall a
$$

Recall that the link flows $x_{a}(\hat{p})$ and the number of trips for each origin-destination pair, $\hat{q}_{r s}$, that make use of transit must be in equilibrium, as given by equations (7)-(11) for the optimal $(\hat{p})$. 


\section{Solution Procedure}

It is important to notice that in the upper level problem, if the headway is fixed, the only decision variables that remain are those associated with the toll prices. If the optimal toll prices generate revenues that are sufficient to cover the costs of the headway assumed, then we have a feasible set of toll prices and associated headway. If insufficient funds result then that particular value of for the headway is discarded. Hence, this solution procedure is based on identifying all possible values for the headway, then for each of these values finding the optimal toll prices. Across all sets of feasible optimal toll prices and associated headways, we then select that set which minimize societal costs (as estimated by the objective function for the upper level problem as given in Equation (12)).

For a given headway, we solve the resultant formulation given in Section 3 via a genetic algorithm. The chromosome is a vector of toll prices, one for each link that can have a positive toll. If the toll prices are given, For a given chromosome, the Frank-Wolfe algorithm is used to solve the lower level problem (Sheffi, 1985) and the upper level objective is then computed.

We randomly generate the first generation. That is, for each individual in the population we randomly generate a toll for each arc that may have a positive toll. We use a single uniform distribution to do this with a lower and upper bound for the toll price on any arc.

In each generation we use tournament selection to identify parents based on the fitness value of an individual, where the fitness is determined using the objective in Equation (12). Each pair of parents that result from the tournament process yields two offspring using arithmetic crossover. More specifically, let $C$ and $D$ be the offspring of parents $A$ and $B$. Let $p_{a}^{k}$ be the toll price on arc $a$ in chromosome $k$. The toll price for arc $a$ for offspring child chromosomes $\mathrm{C}$ and D are then as follows:

$$
\begin{aligned}
& p_{a}^{C}=\omega p_{a}^{A}+(1-\omega) p_{a}^{B} \\
& p_{a}^{D}=(1-\omega) p_{a}^{A}+\omega p_{a}^{B}
\end{aligned}
$$

where $\omega$ is a user defined parameter that is greater than zero and less than one (i.e. $0<\omega<1$ ). 
Mutation of a gene occurs with a user defined probability added to the population and the two least fit members of the population are removed.

\subsection{Illustrative Case Study}

\subsection{Road Network}

To illustrate the formulation and solution procedure given above, we develop an example using the highway network structure for the cordon-based Electronic Road Pricing (ERP) system in downtown Orchard Road, Singapore (Liu. Z., 2011). The structure of that network and the pricing boundary are indicated in Figure 1. The road network has 104 links and 33 nodes.

The dashed line represents the pricing cordon: during the morning peak, any vehicle that passes the cordon to enter the zone is charged, whereas in the evening peak, the vehicles that exit the zone via the cordon are charged. There are a total of 12 links with tolls in the network. We use Figure 1 only to show the scenario of morning peak, thus those 12 charged links are indicated with bold arrows pointing inside the zone.

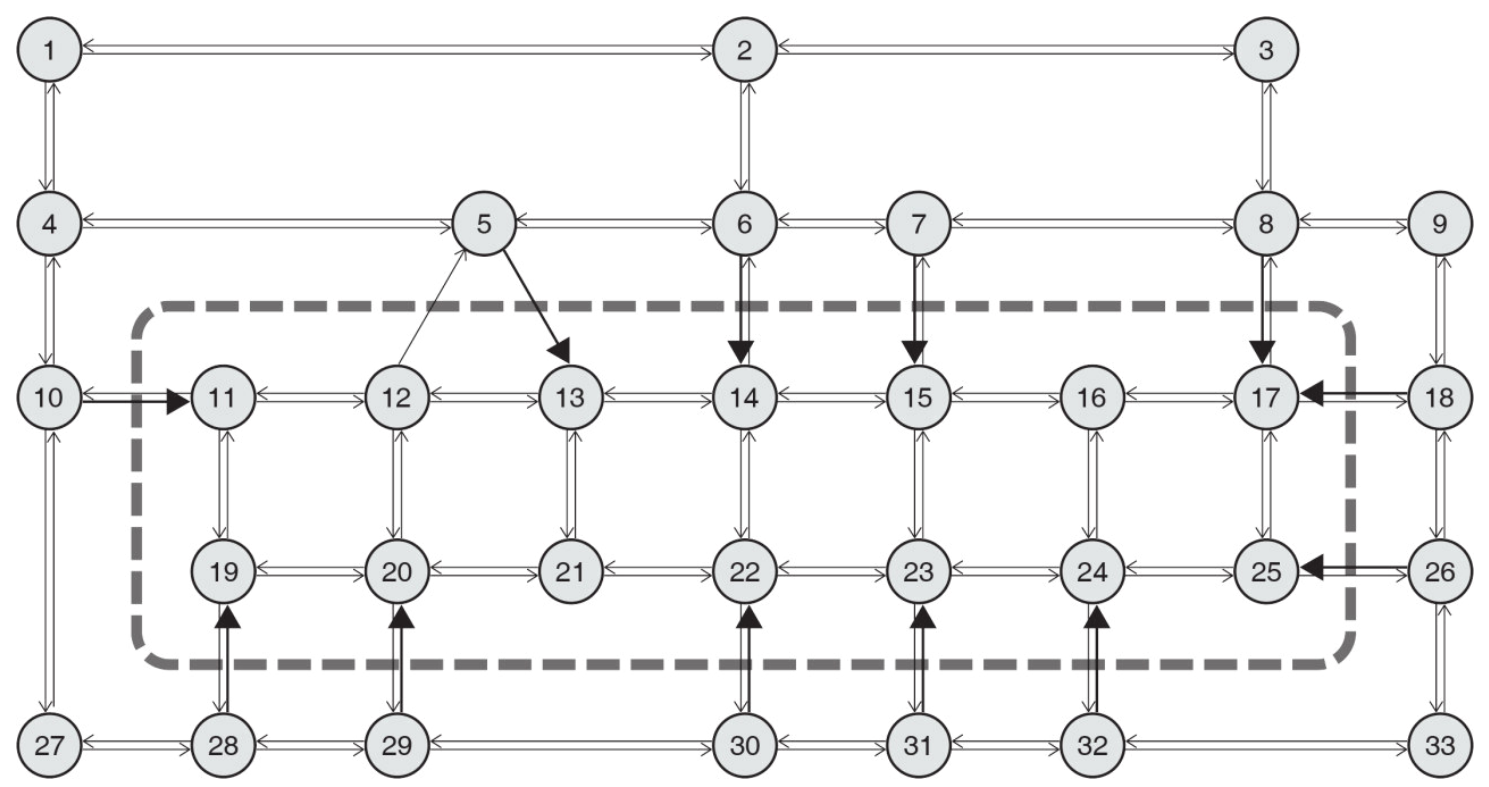

Figure 1. Topological Structure of the Orchard Road Network

Instead of using the link attributes from the referred site directly, we enlarged the network by increasing the free-flow travel time on each link by a factor of four. This modification is done to make transit more desirable because the original headways in the transit system are on the order of 
20 minutes. The modified free-flow travel time, along with the capacity and distance of each link are given in Appendix A. It is important to notice that the links are not drawn to scale in Figure 1. For example, the distance from node 8 to node 17 is 3.3 miles while the distance from nodes 9 to 18 is 5 miles.

To compute link travel times, we use the BPR formula with $\alpha$ and $\beta$ to 0.15 and 4 , respectively and as given in Equation (17).

$$
t_{a}\left(1+0.15\left(\frac{x_{a}}{c_{a}}\right)^{4}\right)
$$

Since the pricing mechanism will only be implemented during the peak hours, we use wages to set the value of time. U.S. average hourly earnings (Bureau of Labor Statistics, 2015) are about \$24.78 per hour. Hence we assume that $v$ is $\$ 24.78$. Moreover, the per mile cost to drive, $c_{d}$, is assumed to be fifty cents (AAA, 2013). We assume that toll prices are no more than $\$ 6$ per link.

Table 2 gives the morning origin-destination table. We assume that the evening origin-destination table is simply the reverse. Notice that there are only 9 origin-destination pairs of similar scale per hour.

Table 2. Parameters in the Travel Demand Function

\begin{tabular}{cc}
\hline $\begin{array}{c}\text { OD pair } \\
\text { r-s }\end{array}$ & $\begin{array}{c}\text { Travel demand } \\
\bar{q}_{r s} \text { (vehicles) }\end{array}$ \\
\hline $3 \rightarrow 14$ & 5,000 \\
$33 \rightarrow 19$ & 9,000 \\
$1 \rightarrow 14$ & 6,000 \\
$30 \rightarrow 17$ & 7,000 \\
$3 \rightarrow 30$ & 7,000 \\
$27 \rightarrow 22$ & 8,000 \\
$30 \rightarrow 11$ & 4,000 \\
$1 \rightarrow 22$ & 7,000 \\
$2 \rightarrow 19$ & 7,000 \\
\hline
\end{tabular}

\subsection{Transit Network}

The transit network is assumed to have at least one route available per origin-destination pair. 
Figure 2 gives the transit network and illustrates its geographical relationship with the road network. The transit network is presented by the thick dark lines and circles, with all lines indicate bidirectional connections. The transit network includes 5 routes, and the detailed route maps are shown in Figure 3.

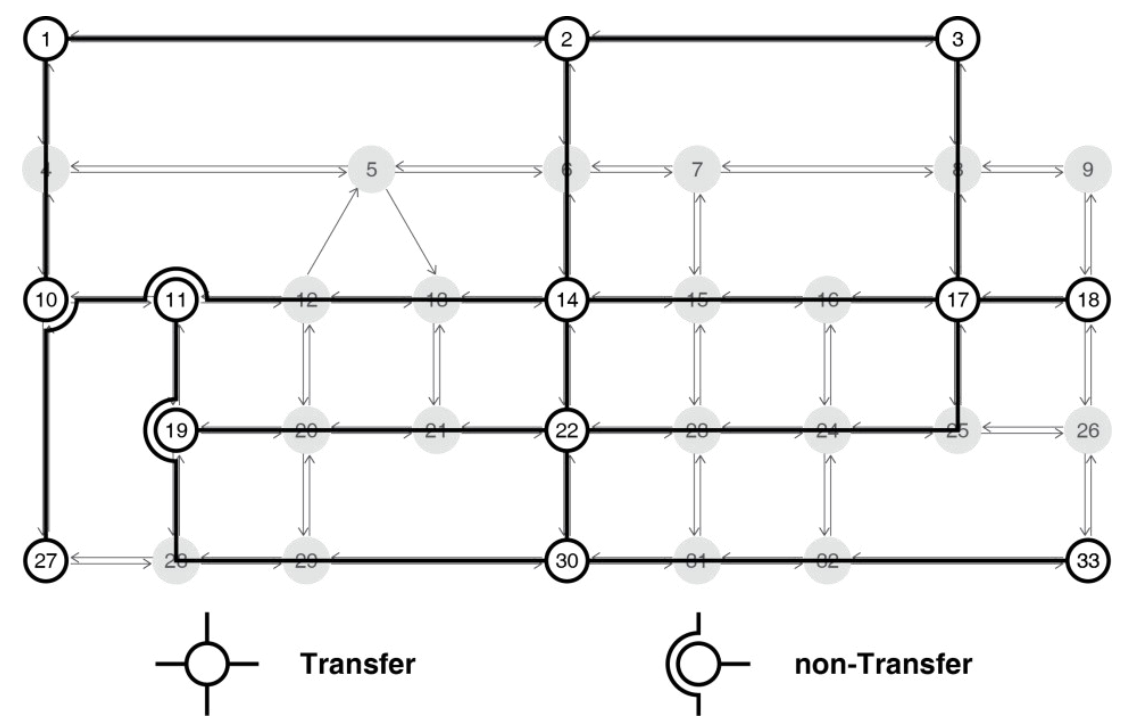

Figure 2. Transit network for study site

We assume that there are no capacity constraints for each route in the transit system (i.e. the individual trains have sufficient capacity to accommodate riders). The operational speed of the transit system is assumed to be 30 miles per hour (Andrew., 2009). In addition, the transit headway is assumed as 20 minutes on each of the 5 routes. Thus, the transit network attributes are given in Table 3.

Table 3. Transit Network Attribute

\begin{tabular}{cccccc}
\hline $\begin{array}{c}\text { Route } \\
\text { No. }\end{array}$ & $\begin{array}{c}\text { Start-End } \\
\text { r-s }\end{array}$ & $\begin{array}{c}\text { Transfer } \\
\text { Available }\end{array}$ & $\begin{array}{c}\text { Stop duration } \\
\text { at each stops (sec) }\end{array}$ & $\begin{array}{c}\text { In-vehicle Travel Time } \\
\text { (min) }\end{array}$ & $\begin{array}{c}\text { Headway } \\
\text { (min) }\end{array}$ \\
\hline 1 & $10 \leftrightarrow 3$ & 1,2 & 20 & 27 & 20 \\
2 & $2 \leftrightarrow 30$ & 14,22 & 20 & 29 & 20 \\
3 & $18 \leftrightarrow 27$ & 14,17 & 20 & 34 & 20 \\
4 & $3 \leftrightarrow 19$ & 17,22 & 20 & 36 & 20 \\
5 & $11 \leftrightarrow 33$ & 30 & 20 & 32 & 20 \\
\hline
\end{tabular}




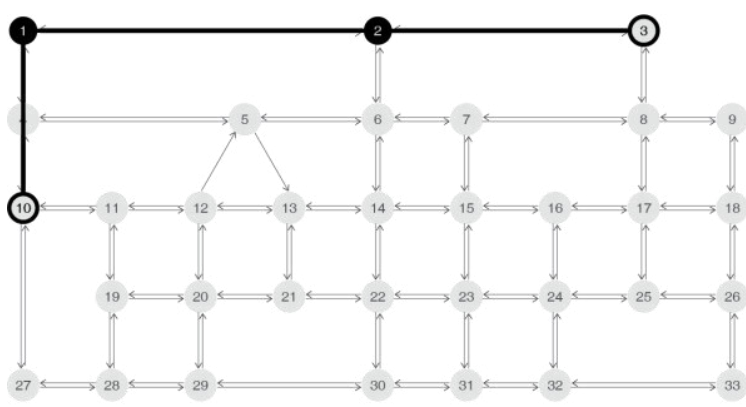

Route 1

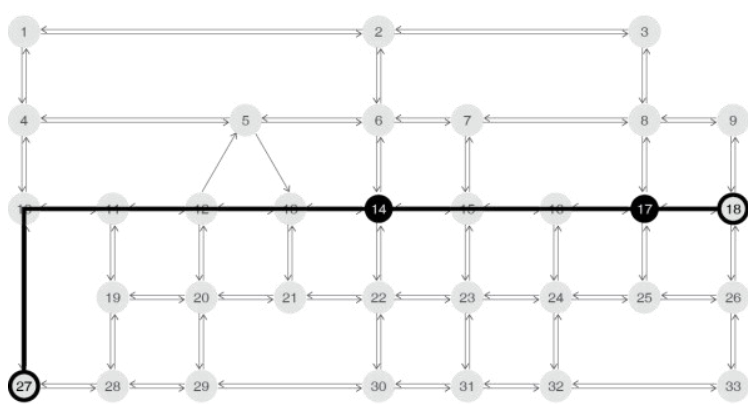

Route 3

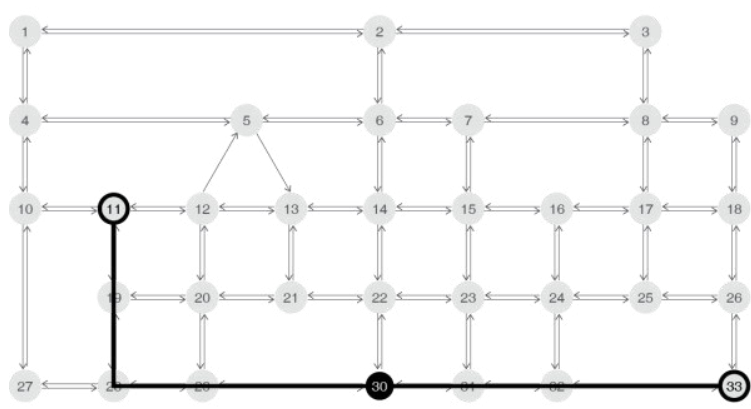

Route 5

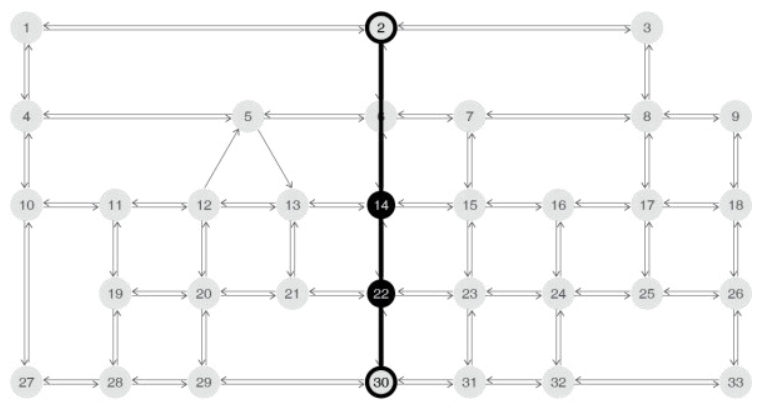

Route 2

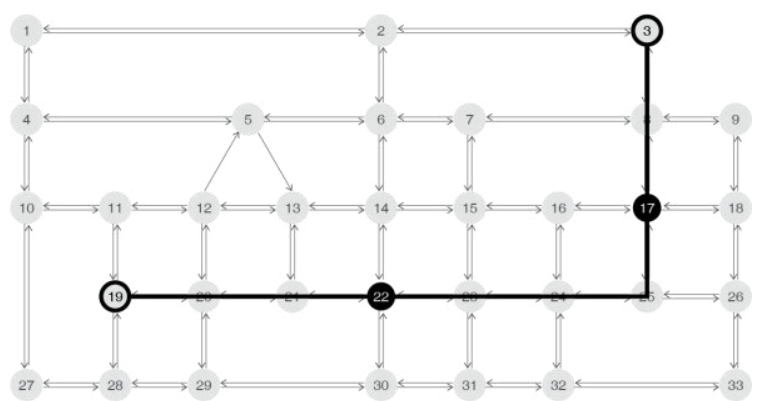

Route 4

Figure 3. Transit Network Route Map

\subsection{Investments to Improve Headways}

As indicated in Table 3, we assume that with no toll revenue, each route has a 20 minute headway. Figure 4 gives the function of $H(\hat{p})$, which illustrates the relationship between certain amounts of toll revenue and transit headway reduction. Assume that an additional tn million dollar investment allows the headways on each route to be reduced to $\frac{1}{t+1}$ of the original headway where $n$ is the cost to half the existing headway. Hence, we assume that the only valid values for the headway are those associated with multiples of $n$. For this specific case, it is assumed that the 
toll revenue would be collected for the morning peak and evening peak (which are both assumed to be three hours in duration) during the week days and therefore at the end of a year, the costs would have been recovered. The next sub section investigates the impact of different values for $n$.

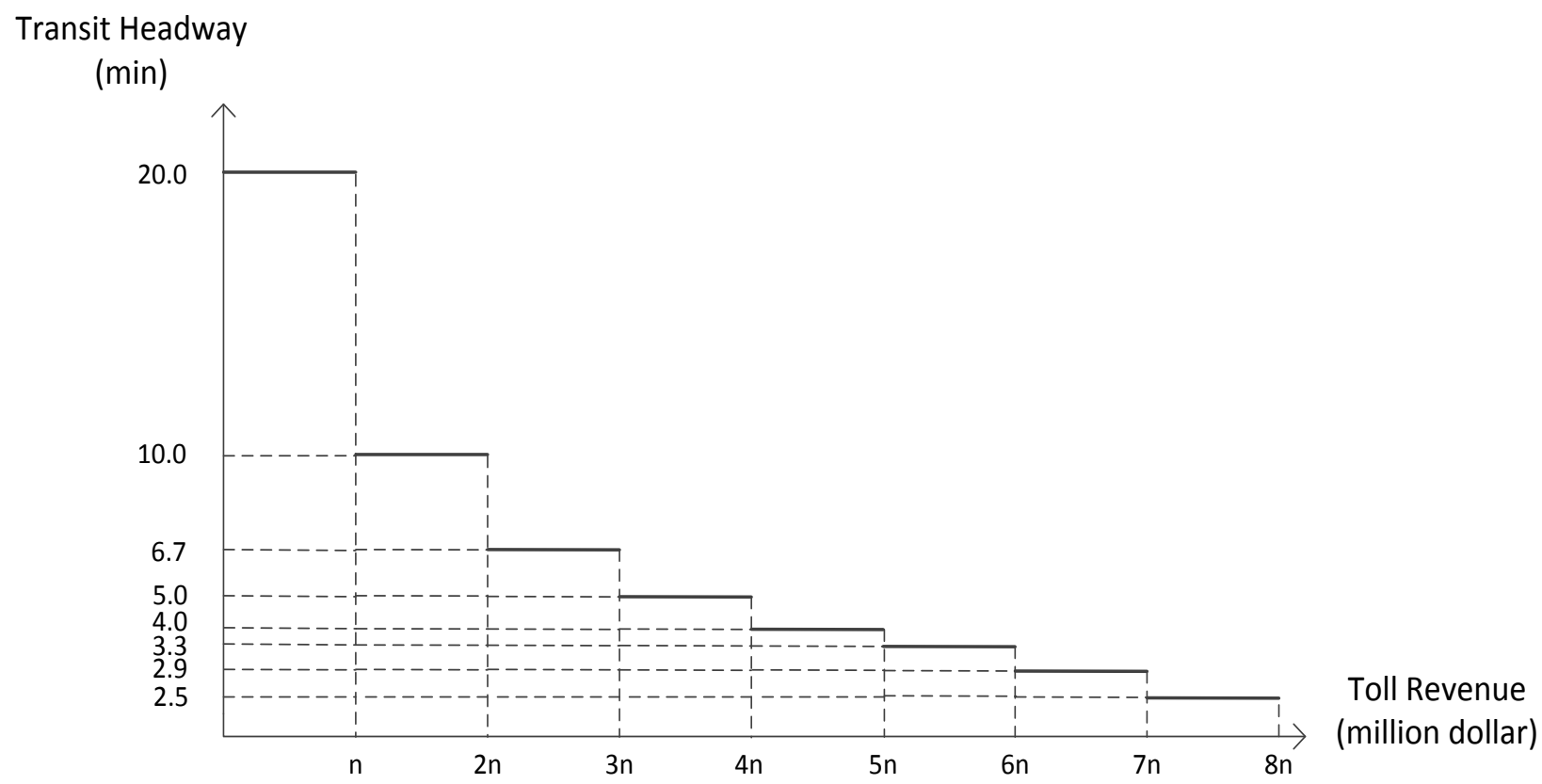

Figure 4. Toll Revenue and Transit Headway deduction

\subsection{Illustrative results}

The parameters for the GA are as follows: the population and the number of generations are each 100 , the tournament size is 5 for each parent, $\omega$ is assumed to be 0.25 , the mutation rate is $5 \%$. If a mutation is to occur, a random value that is normally distributed with a mean of 0 and variance of 2 is added to the existing price of the toll to be mutated.

We run the algorithms for four cases of $n$ as in Figure 4. The four values are 20, 18, 12, and 7. The resultant optimal toll prices for each case are shown in Table 4. The average travel cost for each origin-destination pair and the optimal headway for each case are given in Table 5. Table 6 gives the travel time by mode and origin-destination pair for each case. Table 7 gives the parallel information for travel costs by origin-destination pair for each case. Table 8 gives the number of trips by origin-destination pair and mode for each case.

As shown in Table 3, the initial headway used was 20 minutes per route. Using the toll prices identified via the optimization and given in Table 4, the transit headways are reduced to 6.7 minutes, 
5 minutes, 4 minutes and 2.9 minutes corresponding to $n=20, n=18, n=12$, and $n=7$ as given in Table 5.

In Table 5, it is useful to notice that the average travel cost decrease as $n$ declines because the costs to reduce the headways are declining. This trend holds for each origin-destination pair except for OD pair 30 to 17 . The average cost when $n=20$ is $\$ 8.70$, in contrast to when $n=18$ the average cost is $\$ 9.28$. For both cases, all 7,000 travelers choose the road network with 730 travelers taking path 30-22-23-24-16-17 and 6,270 travelers taking path 30-22-23-15-16. Only link 30-22 has a toll, which is $\$ 0.6$ when $n=20$ but $\$ 1.20$ when $n$ is 18 . This difference in toll is the same as the difference in travel cost between the two solutions. 
Table 4. Optimal Toll Prices for Different Levels of Investment Costs

\begin{tabular}{c|cccc}
\hline \multirow{2}{*}{ Toll Link } & \multicolumn{4}{|c}{ Toll Price } \\
\cline { 2 - 5 } & $\mathrm{n}=20$ & $\mathrm{n}=18$ & $\mathrm{n}=12$ & $\mathrm{n}=7$ \\
\hline $6-14$ & $\$ 1.70$ & $\$ 3.30$ & $\$ 4.00$ & $\$ 3.20$ \\
$31-23$ & $\$ 1.20$ & $\$ 5.40$ & $\$ 1.40$ & $\$ 3.10$ \\
$5-13$ & $\$ 1.30$ & $\$ 6.00$ & $\$ 3.40$ & $\$ 2.30$ \\
$30-22$ & $\$ 0.60$ & $\$ 1.20$ & $\$ 0.70$ & $\$ 0.70$ \\
$32-24$ & $\$ 0.70$ & $\$ 0.60$ & $\$ 1.10$ & $\$ 0.70$ \\
$7-15$ & $\$ 3.40$ & $\$ 1.40$ & $\$ 2.80$ & $\$ 2.20$ \\
$10-11$ & $\$ 3.60$ & $\$ 4.10$ & $\$ 2.10$ & $\$ 2.80$ \\
$8-17$ & $\$ 1.20$ & $\$ 1.10$ & $\$ 0.60$ & $\$ 1.30$ \\
$18-17$ & $\$ 3.10$ & $\$ 5.20$ & $\$ 3.90$ & $\$ 1.30$ \\
\hline
\end{tabular}

Table 5. Average Travel Cost over Modes for Before \& After Tolling

\begin{tabular}{|c|c|c|c|c|c|c|}
\hline \multirow{2}{*}{\multicolumn{2}{|c|}{$\frac{\text { Avg Cost }}{\text { Cases }}$}} & Before & \multicolumn{4}{|c|}{ After } \\
\hline & & No investment & $\mathrm{n}=20$ & $\mathrm{n}=18$ & $\mathrm{n}=12$ & $\mathrm{n}=7$ \\
\hline \multicolumn{2}{|c|}{ Headway } & $20 \mathrm{~min}$ & $6.7 \mathrm{~min}$ & $5 \mathrm{~min}$ & $4 \mathrm{~min}$ & $2.9 \mathrm{~min}$ \\
\hline \multicolumn{2}{|c|}{ OD Pairs } & \multicolumn{5}{|c|}{ Average Travel Cost of each OD (\$) } \\
\hline 3 & 14 & $\$ 18.90$ & $\$ 13.88$ & $\$ 13.20$ & $\$ 12.78$ & $\$ 12.31$ \\
\hline 33 & 19 & $\$ 29.41$ & $\$ 21.68$ & $\$ 20.66$ & $\$ 20.04$ & $\$ 19.34$ \\
\hline 1 & 14 & $\$ 17.3$ & $\$ 12.79$ & $\$ 12.11$ & $\$ 11.69$ & $\$ 11.22$ \\
\hline 30 & 17 & $\$ 8.63$ & $\$ 8.70$ & $\$ 9.28$ & $\$ 8.66$ & $\$ 8.65$ \\
\hline 3 & 30 & $\$ 21.75$ & $\$ 16.44$ & $\$ 15.75$ & $\$ 15.34$ & $\$ 14.83$ \\
\hline 27 & 22 & $\$ 11.13$ & $\$ 11.77$ & $\$ 11.75$ & $\$ 11.34$ & $\$ 10.89$ \\
\hline 30 & 11 & $\$ 8.72$ & $\$ 8.71$ & $\$ 8.38$ & $\$ 8.18$ & $\$ 7.94$ \\
\hline 1 & 22 & $\$ 20.66$ & $\$ 15.67$ & $\$ 14.99$ & $\$ 14.57$ & $\$ 14.10$ \\
\hline 2 & 19 & $\$ 24.95$ & $\$ 19.58$ & $\$ 18.86$ & $\$ 18.48$ & $\$ 18.00$ \\
\hline \multicolumn{2}{|c|}{$\begin{array}{l}\text { Average } \\
\text { Cost }(\$)\end{array}$} & $\$ 18.65$ & $\$ 14.90$ & $\$ 14.39$ & $\$ 13.99$ & $\$ 13.51$ \\
\hline
\end{tabular}


Table 6. Travel Time by Mode Before \& After Tolling

\begin{tabular}{|c|c|c|c|c|c|c|c|c|c|c|c|c|c|c|c|}
\hline \multirow{2}{*}{$\begin{array}{c}\text { TIME } \\
\text { Investment }\end{array}$} & \multirow{2}{*}{\multicolumn{3}{|c|}{$\begin{array}{c}\text { Before: Travel Time (min) } \\
\text { No Investment }\end{array}$}} & \multicolumn{12}{|c|}{ After: Travel Time (min) } \\
\hline & & & & \multicolumn{3}{|c|}{$\mathrm{n}=20$} & \multicolumn{3}{|c|}{$\mathrm{n}=18$} & \multicolumn{3}{|c|}{$\mathrm{n}=12$} & \multicolumn{3}{|c|}{$\mathrm{n}=7$} \\
\hline Headway & \multicolumn{3}{|c|}{$20 \mathrm{~min}$} & \multicolumn{3}{|c|}{$6.7 \mathrm{~min}$} & \multicolumn{3}{|c|}{$5 \mathrm{~min}$} & \multicolumn{3}{|c|}{$4 \min$} & \multicolumn{3}{|c|}{$2.9 \mathrm{~min}$} \\
\hline OD Pair & Autc & Transit & Average & Auto & Transit & Average & Auto & Transit & Average & Auto & Transit & Average & Auto & Transit & Average \\
\hline $3 \rightarrow 14$ & 28.39 & 46.89 & 28.39 & 17.34 & 33.56 & 33.56 & 16.62 & 31.89 & 31.89 & 16.74 & 30.89 & 30.89 & 16.27 & 29.75 & 29.75 \\
\hline \multirow{2}{*}{$\begin{aligned} 33 & \rightarrow 19 \\
1 & \rightarrow 14\end{aligned}$} & 43.7 & 72.44 & 43.71 & 28.75 & 52.44 & 37.47 & 25.72 & 49.94 & 34.94 & 22.47 & 48.44 & 36.03 & 22.59 & 46.73 & 35.69 \\
\hline & 26.32 & 44.22 & 26.32 & 14.67 & 30.89 & 30.89 & 14.67 & 29.22 & 29.22 & 14.67 & 28.22 & 28.22 & 14.67 & 27.08 & 27.08 \\
\hline \multirow{2}{*}{$\begin{array}{c}30 \rightarrow 17 \\
3 \rightarrow 30\end{array}$} & 11.5 & 38.00 & 11.51 & 10.61 & 24.67 & 10.61 & 10.06 & 23.00 & 10.06 & 10.57 & 22.00 & 10.57 & 10.07 & 20.86 & 11.47 \\
\hline & 34.7 & 53.20 & 38.36 & 19.31 & 39.87 & 29.57 & 17.95 & 38.20 & 30.92 & 18.13 & 37.20 & 29.74 & 17.47 & 36.06 & 36.06 \\
\hline \multirow{2}{*}{$\begin{array}{l}27 \rightarrow 22 \\
30 \rightarrow 11\end{array}$} & 15.7 & 43.33 & 15.74 & 14.09 & 30.00 & 14.09 & 14.27 & 28.33 & 15.11 & 11.65 & 27.33 & 13.65 & 10.85 & 26.19 & 14.30 \\
\hline & 11.21 & 27.67 & 11.20 & 10.23 & 21.00 & 18.39 & 9.63 & 20.17 & 20.17 & 10.14 & 19.67 & 19.67 & 9.88 & 19.10 & 19.10 \\
\hline \multirow{2}{*}{$\begin{array}{l}1 \rightarrow 22 \\
2 \rightarrow 19 \\
\end{array}$} & 30.39 & 51.22 & 30.39 & 18.32 & 37.89 & 37.89 & 18.67 & 36.22 & 36.22 & 18.05 & 35.22 & 35.22 & 17.95 & 34.08 & 34.08 \\
\hline & 42.32 & 60.76 & 46.49 & 23.94 & 47.43 & 28.22 & 21.14 & 45.76 & 29.66 & 20.89 & 44.76 & 26.61 & 21.21 & 43.62 & 27.06 \\
\hline Avg Travel Time & \multicolumn{3}{|c|}{$29.18 \mathrm{~min}$} & \multicolumn{3}{|c|}{$27.01 \quad \min$} & \multicolumn{3}{|c|}{$26.65 \mathrm{~min}$} & \multicolumn{3}{|c|}{$25.85 \mathrm{~min}$} & \multicolumn{3}{|c|}{$26.40 \mathrm{~min}$} \\
\hline
\end{tabular}

\begin{tabular}{|c|c|c|c|c|c|c|c|c|c|c|}
\hline \multirow{2}{*}{$\begin{array}{l}\text { Travel Cost } \\
\text { Investment }\end{array}$} & \multicolumn{2}{|c|}{ Before } & \multicolumn{8}{|c|}{ After } \\
\hline & \multicolumn{2}{|c|}{ No Investment } & \multicolumn{2}{|c|}{$\mathrm{n}=20$} & \multicolumn{2}{|c|}{$\mathrm{n}=18$} & \multicolumn{2}{|c|}{$\mathrm{n}=12$} & \multicolumn{2}{|c|}{$\mathrm{n}=7$} \\
\hline Headway & \multicolumn{2}{|c|}{$20 \mathrm{~min}$} & \multicolumn{2}{|c|}{$6.7 \mathrm{~min}$} & \multicolumn{2}{|c|}{$5 \min$} & \multicolumn{2}{|c|}{$4 \min$} & \multicolumn{2}{|c|}{$2.9 \mathrm{~min}$} \\
\hline OD Pair & Auto & Transit & Auto & Transit & Auto & Transit & Auto & Transit & Auto & Transit \\
\hline $3 \rightarrow 14$ & $\$ 18.95$ & $\$ 19.39$ & $\$ 15.26$ & $\$ 13.88$ & $\$ 14.74$ & $\$ 13.2$ & $\$ 14.31$ & $\$ 12.78$ & $\$ 14.78$ & $\$ 12.31$ \\
\hline $33 \rightarrow 19$ & $\$ 29.41$ & $\$ 29.91$ & $\$ 21.70$ & $\$ 21.65$ & $\$ 20.68$ & $\$ 20.62$ & $\$ 20.09$ & $\$ 20$ & $\$ 19.40$ & $\$ 19.29$ \\
\hline $1 \rightarrow 14$ & $\$ 17.31$ & $\$ 18.30$ & $\$ 13.89$ & $\$ 12.79$ & $\$ 15.50$ & $\$ 12.11$ & $\$ 16.19$ & $\$ 11.69$ & $\$ 15.36$ & $\$ 11.22$ \\
\hline $30 \rightarrow 17$ & $\$ 8.63$ & $\$ 15.74$ & $\$ 8.70$ & $\$ 10.23$ & $\$ 9.28$ & $\$ 9.55$ & $\$ 8.67$ & $\$ 9.13$ & $\$ 8.65$ & $\$ 8.66$ \\
\hline $3 \rightarrow 30$ & $\$ 21.71$ & $\$ 21.91$ & $\$ 16.48$ & $\$ 16.4$ & $\$ 15.79$ & $\$ 15.72$ & $\$ 15.39$ & $\$ 15.3$ & $\$ 15.78$ & $\$ 14.83$ \\
\hline $27 \rightarrow 22$ & $\$ 11.13$ & $\$ 17.93$ & $\$ 11.77$ & $\$ 12.42$ & $\$ 11.75$ & $\$ 11.74$ & $\$ 11.34$ & $\$ 11.32$ & $\$ 10.90$ & $\$ 10.85$ \\
\hline $30 \rightarrow 11$ & $\$ 8.72$ & $\$ 11.48$ & $\$ 8.77$ & $\$ 8.73$ & $\$ 9.13$ & $\$ 8.38$ & $\$ 8.88$ & $\$ 8.18$ & $\$ 8.76$ & $\$ 7.94$ \\
\hline $1 \rightarrow 22$ & $\$ 20.66$ & $\$ 21.18$ & $\$ 16.13$ & $\$ 15.67$ & $\$ 18.81$ & $\$ 14.99$ & $\$ 17.27$ & $\$ 14.57$ & $\$ 17.05$ & $\$ 14.10$ \\
\hline $2 \rightarrow 19$ & $\$ 24.93$ & $\$ 25.02$ & $\$ 19.59$ & $\$ 19.51$ & $\$ 18.88$ & $\$ 18.83$ & $\$ 18.5$ & $\$ 18.41$ & $\$ 18.02$ & $\$ 17.94$ \\
\hline
\end{tabular}




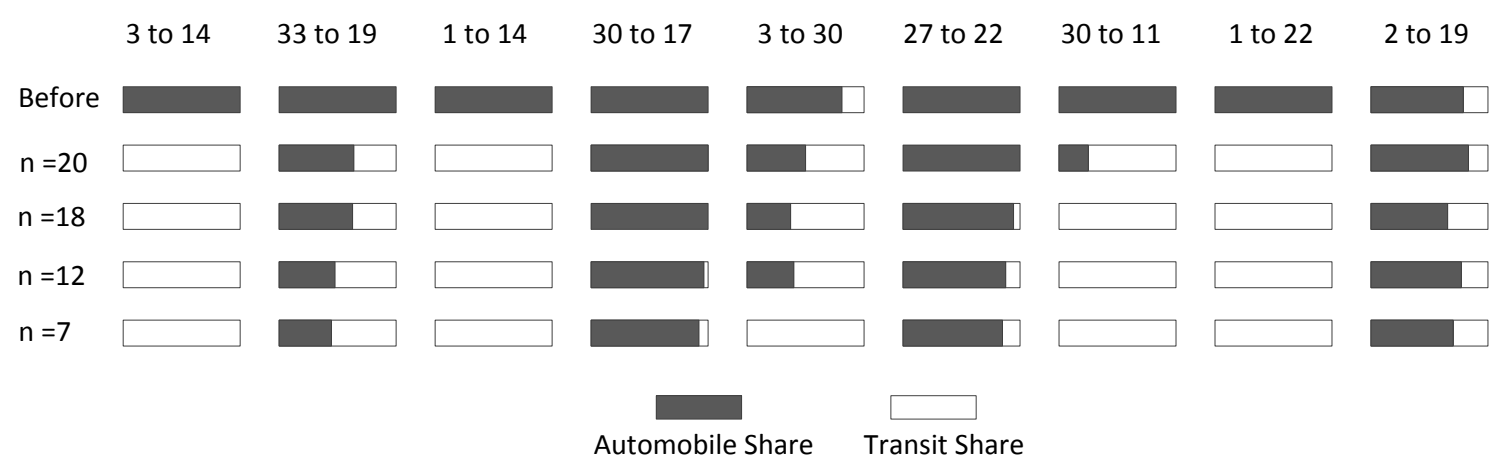

Figure 5. Number of Trips by Mode for Before \& After Tolling

Table 6 gives the travel time by mode before and after the implementation of tolls for each of the four cases. The last row shows the average travel time for all travelers for all cases. It is important to notice that the average travel time is decreasing as the costs to reduce headways declines, except for the last case where $n=7$. The average travel time for each OD pair when $n=7$ is higher mainly due to OD pairs 3 to 30 . Table 7, which gives the travel cost by mode, illustrates that for OD pairs 3 to $30, n=7$ the travel cost for using automobile increasing while the travel cost for using transit decrease and therefore no trip adopt automobile as illustrated by Figure 6. However, as indicated in Table 6, transit travel time is higher than automobiles, therefore the average travel time for OD pairs 3 to 30 increases.

Figure 5 gives the share of trips for each origins-destination pair by automobile and transit. It is useful to notice that prior to the implementation of the tolls, transit is only attractive to two origin-destination pairs. For each origin-destination pair, an increasing number of trips move to transit as the investment needed to reduce the headways declines The number of trips on transit is about 3,000 before tolling, and is about 29,000,33,000,34,000, and 38,000 when $n=20, n=$ $18, n=12$, and $n=7$, respectively. Notice that the number of trips we use here and following are only for one peak.

Figure 6 and Figure 7 give the link volumes in the road and transit network before and after the tolls are implemented when $n=7$. It is obvious that transit becomes more attractive after tolls are instituted on the road network and the headways are adjusted. Before the implementation of the tolls and related investments, only routes 2 and 4 are adopted by travelers, and the number of trips on 
both routes is about 2,900. However, in the case when $n=7$, all five routes are used and the number of trips on routes $1,2,3,4$ and 5 is about 13,000, 29,400,6,800, 19,600 and 4,000, respectively. Similarly, as shown in Figure 7, it is clear that tolls have reduced the congestion in the road network substantially. As shown in Figure 7, among the 103 links in the networks, while 2\% of the links have higher volume, $32 \%$ of the links experience volume reductions of at least $90 \%$. For about $40 \%$ of the links the reduction exceeds $50 \%$, and for about $48 \%$ of the links the reduction exceeds $30 \%$. 


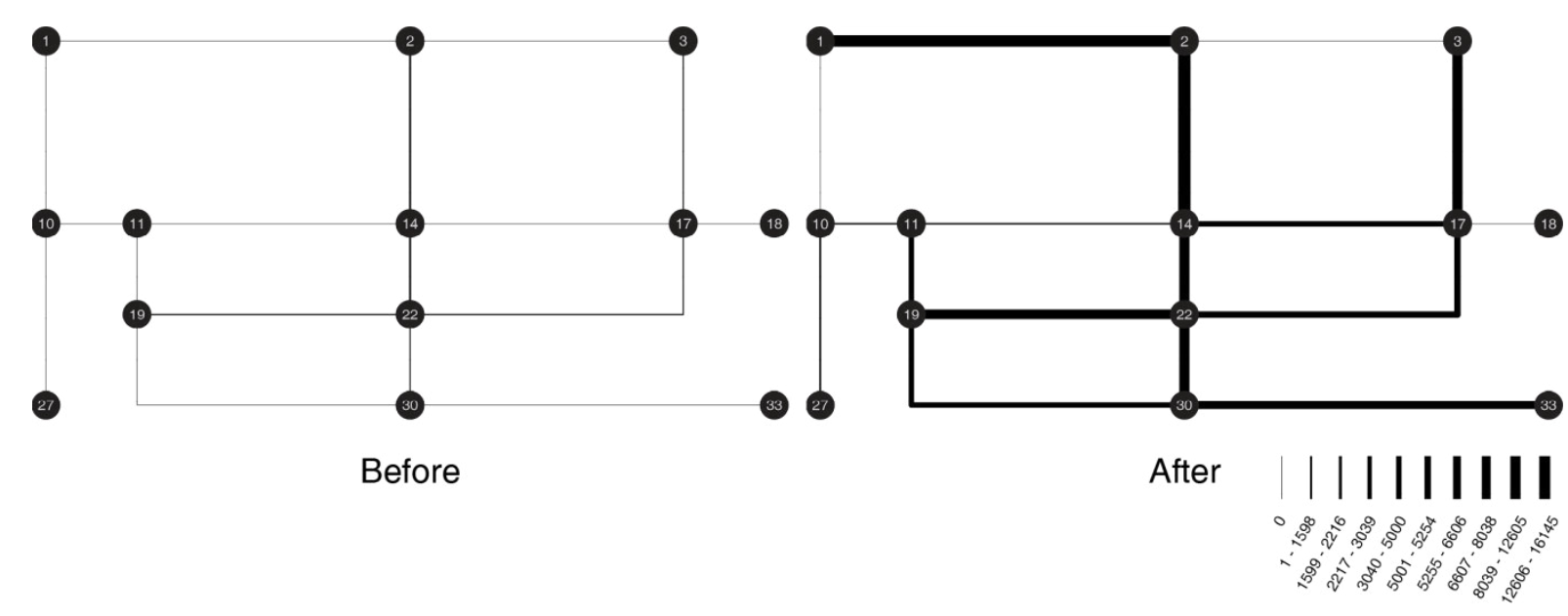

Figure 6. Transit Volumes Before \& After for Case $n=7$
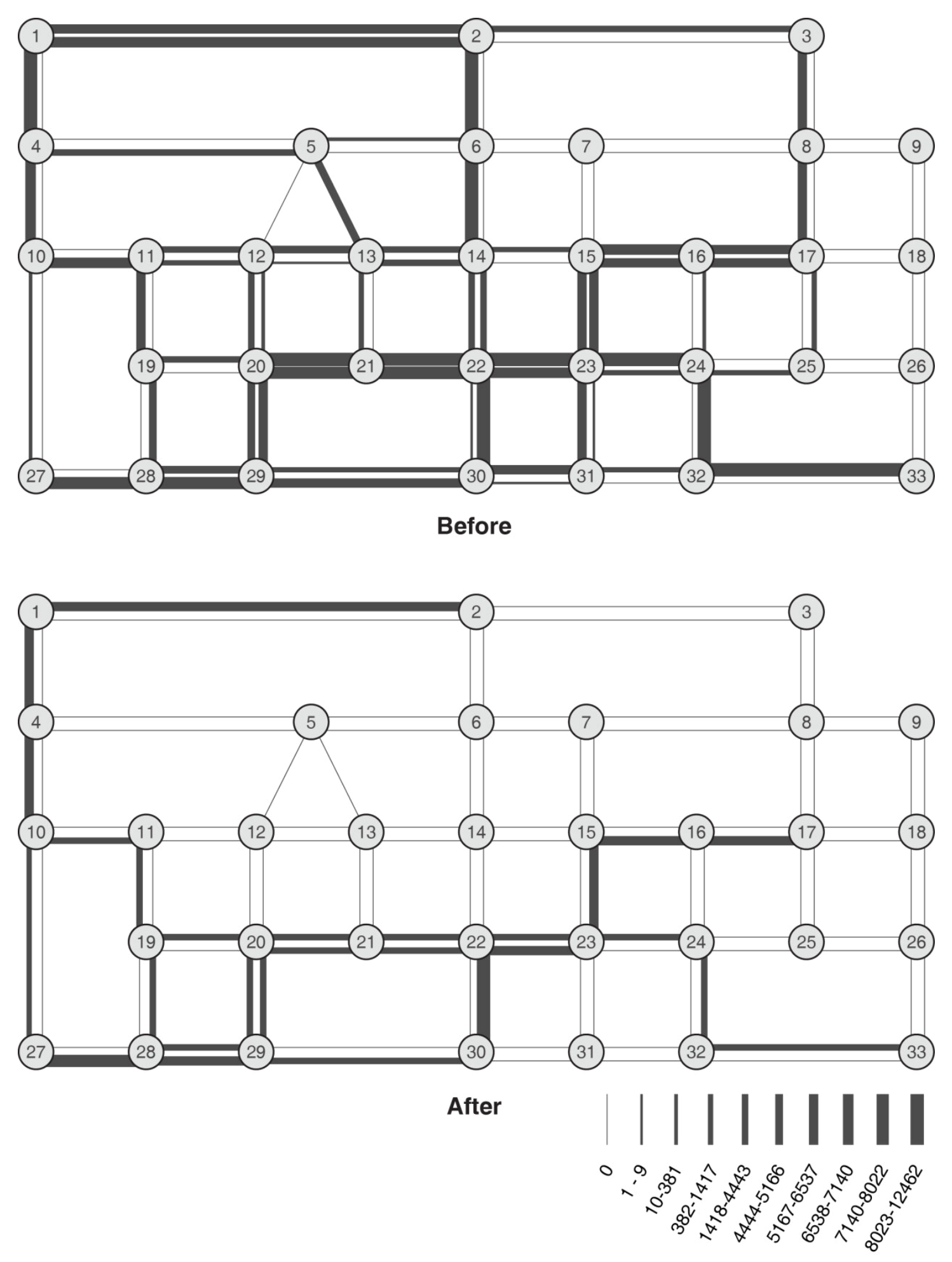

Figure 7. Traffic Volumes in the Road Network Before \& After for $\mathrm{n}=7$ 


\subsection{Conclusions and Next Steps}

We develop a bi-level optimization model to address the challenges in congestion pricing, including establishing prices and addressing inequities that can stem from those prices. The upper level model maximizes social welfare by choosing toll price and investment levels in an associated transit network. The lower level computes the mode split and link assignment. The solution procedure is an integration of a genetic algorithm with the Frank-Wolfe method. We apply both the model and its solution procedure to an illustrative example. There is empirical research that has established the benefit of public transportation in alleviating congestion. The illustrative example also confirms this opportunity. This illustrative example, also demonstrates the opportunities associated with jointly planning pricing for the road network with investments in alternative forms of transportation.

There are opportunities for future research in at least five areas. First, we focus on an average value of time. In practice different individuals have different values for time. Because neighborhoods are often stratified by this value of time, it may be important to let the value of time vary by origin-destination pair and make the fare price a subject of the optimization. Second, people value waiting time differently than in-vehicle time. Expanding the modeling to address these differences is likely to prove useful. Third, we assume that the demands are static and deterministic. In practice, they are dynamic and stochastic. Similarly, the transit schedule is assumed to be fixed over the day and all routes are assumed to have the same headways. In practice, transit schedules should be allowed to vary across time periods and headways should be route specific. Also, additional routes should be considered for inclusion. Fourth, we use an expected transit travel time and users make no use of dynamic information while navigating the transit system. In large transit systems, users often adopt policies of what trains to take based on dynamic estimates of remaining travel time on different routes as they navigate the transit system. Finally, we make use of a genetic algorithm as part of the optimization. As the networks get more complicated it may be important to use a more computationally efficient approach. 
Reference

AAA, "Your Driving Costs: How Much Are You Really Paying to Drive", 2013 edition, accessed electronically at http://exchange.aaa.com/wp-content/uploads/2013/04/your-driving-costs-2013.pdf on May $1^{\text {st }}, 2015$.

Adler, J. L., and Cetin, M. A direct redistribution model of congestion pricing. Transportation Research, 35B, 447-460, 2001.

Andrew S., "Train speeds: Do PATH and NY Subway measure up? ", Metropolitan Walker, July 12, 2009 , accessed electronically at http://www.metropolitanwalks.com/blog/train-speeds-do-path-and-ny-subway-measure-up/on July $1^{\text {st }}, 2015$.

Arnott, R., and Small, K. "The Economics of Traffic Congestion.” American Scientist, 82:446-455, 1994.

Bard, J.F. Practical Bilevel optimization: algorithms and applications. Kluwer Academic Publishers, Dordrecht, 1998.

Basar, T. and Srikant , R., A stackelberg network game with a large number of followers. Journal of Optimization Theory and Applications, 115:479-490, 2002.

Bernstein, D. Congestion pricing with tolls and subsidies. In: Proceedings of the Pacific Rim Transportation Technology Conference, 2, 145-151, 1993.

Bureau of Labor Statistics, "US Average Hourly Earnings Chart", Ycharts, accessed electronically at http://ycharts.com/indicators/average_hourly_earnings on February $15^{\text {th }}, 2015$.

Cesario, F. J. "Value of Time in Recreation Studies." Land Econ. 52:32-41, 1976.

Cole, R., Dodis, Y and Roughgarden, T., Pricing network edges for heterogeneous selfish users. Proc. of STOC, 2003.

Confessore, N. "Congestion Pricing Plan Is Dead, Assembly Speaker Says", The New York Times, April $7^{\text {th }}, 2008$

DeCorla-Souza, P. Applying the cashing out approach to congestion pricing. Transportation Research Record, 1450, 34-37, 1995.

Eliasson, J. Road pricing with limited information and heterogeneous users: A successful case. Annals of Regional Science, 35, 595-604, 2001.

Fielding, G. J., "Congestion Pricing and the Future of Transit", Journal of Transport Geography, Vol. 3(4), pp. 239-246, 1995.

Goodwin, P. The rule of three: A possible solution to the political problem of competing objectives for road pricing. Traffic Engineering and Control, 30, 495-497, 1989.

Guerrini, F., "Traffic Congestion Costs Americans \$124 Billion a Year, Report Says", Forbes, accessed electronically on July 1, 2015 at http://www.forbes.com/sites/federicoguerrini/2014/10/14/traffic-congestion-costs-americans-124-bil 
lion-a-year-report-says/ on July $1^{\text {st }}, 2015$.

Hearn, D.W. and Ramana, M.V., Solving congestion toll pricing models. In P. Marcotte and S. Nguyen, editors, Proc. of the Equilibrium and Advanced Transportation Modelling Colloquium, pp. 109-124, 1998.

Kalmanje, S., \& Kockelman, K. Credit-based congestion pricing: Travel, land value and welfare impacts. Transportation Research Record, 1864, 45-53, 2004.

Litman, T. Using road pricing revenue: Economic efficiency and equity considerations. Transportation Research Record 1558, 24-28, 1996.

Liu, Y., Guo, X., Yang, H. Pareto-improving and revenue-neutral congestion pricing schemes in bi-modal traffic networks. Netnomics 10 (1), 123-140, 2009.

Liu, Z., "Probit-based stochastic user equilibrium problems and their applications in congestion pricing", dissertation for doctor of philosophy in the department of civil and environmental engineering national university of Singapore, 2011.

Luo, Z.Q., Pang, J.S. and Ralph, D. Mathematical Programs with Equilibrium Constraints. Cambridge University Press, New York, 1996.

Lydall, R., "Congestion Charge 'has cost drivers $£ 2.6 \mathrm{bn}$ in decade but failed to cut traffic jams"', London Evening Standard, February 15, 2013, accessed electronically at http://www.standard.co.uk/news/transport/congestion-charge-has-cost-drivers-26bn-in-decadebut-failed-to-cut-traffic-jams-8496627.html on July $1^{\text {st }}, 2015$.

Marchand, M. A note on optimal tolls in an imperfect environment. Econometrica, 36, 575-581, 1968.

Nie, Y., Liu, Y. Existence of self-financing and Pareto-improving congestion pricing: impact of value of time distribution. Transportation Research Part A 44 (1), 39-51, 2010.

Parry, I.W.H., Bento, A. Revenue recycling and the welfare effects of road pricing. Working Papers-Public Sector Management. Decentralization, participatory planning. World Bank, 1999.

Poole, R. W. Introducing congestion pricing on a new toll road. Transportation, 19, 383-396, 1992.

Rand Corporation \& Volpe National Transportation Systems Center. "Congestion pricing: Revenue potential (Commission briefing paper 5A-08)", Prepared for the Section 1909 Commission, U.S. Department of Transportation, Washington, DC. January $31^{\text {st }}, 2007$.

Schrank, D., Eisele, B., and Lomax, T., "TTI's 2012 URBAN MOBILITY REPORT”, December 2012, accessed electronically at http://d2dt15nnlpfr0r.cloudfront.net/tti.tamu.edu/documents/mobility-report-2012.pdf on July $1^{\text {st }}$, 2015.

Sheffi, Y., Urban Transportation Networks: Equilibrium Analysis with Mathematical Programming Methods. Prentice-Hall, Englewood Cliffs, NJ, 1985.

Shimizu, K., Ishizuka,Y. and Bard, J.F. Nondifferentiable and two-level mathematical programming. Kluwer Academic Publishers, Boston, 1997.

Small, K. A. "Using the Revenues from Congestion Pricing." Transportation, 19(4):258-81, 1992. 
US Department of Transportation, Federal Highway Administration, "Income-Based Equity Impacts of Congestion Pricing, A Primer", December, 2008

Verhoef, E.T., Bliemer, M., Steg, L., and Wee, B. Pricing in road transport: a multi-disciplinary perspective. Edward Elgar, Cheltenham, UK, Northampton, MA, USA, 2008.

Walters, A.A., "The theory and measurement of private and social cost of highway congestion", Econometrica 29, 676-699, 1961

Yang, H. and Huang, H.J., Principle of marginal-cost pricing: How does it work in a general network? Transportation Research Part A, 32, 45-54. 1998.

Yang H. Meng Q., and Timothy D. H. Optimal integrated pricing in a bi-modal transportation network. Urban and regional transportation modeling, 2004. 


\section{Appendix A}

Table A1. Data for the Link Attributes

\begin{tabular}{|c|c|c|c|c|}
\hline Start node & End node & $\begin{array}{c}\text { Free-flow travel time; } \\
t_{a} \text { (Seconds) }\end{array}$ & $\begin{array}{c}\text { Capacity } \\
C_{a} \text { (Vehicles/hour) }\end{array}$ & $\begin{array}{l}\text { Distance } \\
c_{a} \text { (mile) }\end{array}$ \\
\hline 1 & 2 & 240 & 5400 & 3.33 \\
\hline 1 & 4 & 160 & 5400 & 2.22 \\
\hline 2 & 1 & 240 & 5400 & 3.33 \\
\hline 2 & 3 & 400 & 5400 & 5.56 \\
\hline 2 & 6 & 320 & 7200 & 4.44 \\
\hline 3 & 2 & 400 & 5400 & 5.56 \\
\hline 3 & 8 & 288 & 3600 & 4.00 \\
\hline 4 & 1 & 160 & 5400 & 2.22 \\
\hline 4 & 5 & 360 & 3600 & 5.00 \\
\hline 4 & 10 & 320 & 5400 & 4.44 \\
\hline 5 & 4 & 360 & 3600 & 5.00 \\
\hline 5 & 6 & 168 & 3600 & 2.33 \\
\hline 5 & 13 & 220 & 3600 & 3.06 \\
\hline 6 & 5 & 168 & 3600 & 2.33 \\
\hline 6 & 2 & 320 & 7200 & 4.44 \\
\hline 6 & 7 & 640 & 1800 & 8.89 \\
\hline 6 & 14 & 320 & 7200 & 4.44 \\
\hline 7 & 6 & 640 & 1800 & 8.89 \\
\hline 7 & 8 & 480 & 1800 & 6.67 \\
\hline 7 & 15 & 480 & 1800 & 6.67 \\
\hline 8 & 3 & 288 & 3600 & 4.00 \\
\hline 8 & 7 & 480 & 1800 & 6.67 \\
\hline 8 & 9 & 240 & 3600 & 3.33 \\
\hline 8 & 17 & 240 & 3600 & 3.33 \\
\hline 9 & 8 & 240 & 3600 & 3.33 \\
\hline 9 & 18 & 360 & 3600 & 5.00 \\
\hline 10 & 4 & 320 & 5400 & 4.44 \\
\hline 10 & 11 & 64 & 5400 & 0.89 \\
\hline 10 & 27 & 240 & 5400 & 3.33 \\
\hline 11 & 10 & 64 & 5400 & 0.89 \\
\hline 11 & 12 & 160 & 5400 & 2.22 \\
\hline 11 & 19 & 96 & 1800 & 1.33 \\
\hline 12 & 5 & 220 & 3600 & 3.06 \\
\hline 12 & 11 & 160 & 5400 & 2.22 \\
\hline 12 & 13 & 96 & 5400 & 1.33 \\
\hline 12 & 20 & 80 & 5400 & 1.11 \\
\hline 13 & 12 & 96 & 5400 & 1.33 \\
\hline 13 & 14 & 192 & 5400 & 2.67 \\
\hline 13 & 21 & 120 & 3600 & 1.67 \\
\hline 14 & 6 & 320 & 7200 & 4.44 \\
\hline 14 & 13 & 192 & 5400 & 2.67 \\
\hline 14 & 15 & 160 & 5400 & 2.22 \\
\hline 14 & 22 & 240 & 7200 & 3.33 \\
\hline 15 & 7 & 480 & 1800 & 6.67 \\
\hline
\end{tabular}




\begin{tabular}{|c|c|c|c|c|}
\hline 15 & 14 & 160 & 5400 & 2.22 \\
\hline 15 & 16 & 48 & 5400 & 0.67 \\
\hline 15 & 23 & 48 & 3600 & 0.67 \\
\hline 16 & 15 & 48 & 5400 & 0.67 \\
\hline 16 & 17 & 240 & 5400 & 3.33 \\
\hline 16 & 24 & 48 & 3600 & 0.67 \\
\hline 17 & 8 & 240 & 3600 & 3.33 \\
\hline 17 & 16 & 240 & 5400 & 3.33 \\
\hline 17 & 18 & 240 & 5400 & 3.33 \\
\hline 17 & 25 & 400 & 3600 & 5.56 \\
\hline 18 & 9 & 360 & 3600 & 5.00 \\
\hline 18 & 17 & 240 & 5400 & 3.33 \\
\hline 18 & 26 & 80 & 5400 & 1.11 \\
\hline 19 & 11 & 96 & 1800 & 1.33 \\
\hline 19 & 20 & 320 & 1800 & 4.44 \\
\hline 19 & 28 & 96 & 1800 & 1.33 \\
\hline 20 & 12 & 80 & 5400 & 1.11 \\
\hline 20 & 19 & 320 & 1800 & 4.44 \\
\hline 20 & 21 & 80 & 5400 & 1.11 \\
\hline 20 & 29 & 48 & 5400 & 0.67 \\
\hline 21 & 13 & 120 & 3600 & 1.67 \\
\hline 21 & 20 & 80 & 5400 & 1.11 \\
\hline 21 & 22 & 192 & 5400 & 2.67 \\
\hline 22 & 14 & 48 & 7200 & 0.67 \\
\hline 22 & 21 & 192 & 5400 & 2.67 \\
\hline 22 & 23 & 80 & 5400 & 1.11 \\
\hline 22 & 30 & 240 & 7200 & 3.33 \\
\hline 23 & 15 & 48 & 3600 & 0.67 \\
\hline 23 & 22 & 80 & 5400 & 1.11 \\
\hline 23 & 24 & 112 & 5400 & 1.56 \\
\hline 23 & 31 & 64 & 3600 & 0.89 \\
\hline 24 & 16 & 48 & 3600 & 0.67 \\
\hline 24 & 23 & 112 & 5400 & 1.56 \\
\hline 24 & 25 & 240 & 5400 & 3.33 \\
\hline 24 & 32 & 72 & 5400 & 1.00 \\
\hline 25 & 17 & 56 & 3600 & 0.78 \\
\hline 25 & 24 & 240 & 5400 & 3.33 \\
\hline 25 & 26 & 240 & 5400 & 3.33 \\
\hline 26 & 18 & 80 & 5400 & 1.11 \\
\hline 26 & 25 & 240 & 5400 & 3.33 \\
\hline 26 & 33 & 240 & 5400 & 3.33 \\
\hline 27 & 10 & 240 & 5400 & 3.33 \\
\hline 27 & 28 & 80 & 5400 & 1.11 \\
\hline 28 & 19 & 96 & 1800 & 1.33 \\
\hline 28 & 27 & 80 & 5400 & 1.11 \\
\hline 28 & 29 & 160 & 5400 & 2.22 \\
\hline 29 & 20 & 48 & 5400 & 0.67 \\
\hline 29 & 28 & 160 & 5400 & 2.22 \\
\hline 29 & 30 & 360 & 3600 & 5.00 \\
\hline 30 & 22 & 72 & 7200 & 1.00 \\
\hline 30 & 29 & 360 & 3600 & 5.00 \\
\hline
\end{tabular}




\begin{tabular}{llcll}
\hline 30 & 31 & 240 & 3600 & 3.33 \\
31 & 23 & 64 & 3600 & 0.89 \\
31 & 30 & 120 & 3600 & 1.67 \\
31 & 32 & 240 & 3600 & 3.33 \\
32 & 24 & 72 & 5400 & 1.00 \\
32 & 31 & 240 & 3600 & 3.33 \\
32 & 33 & 384 & 5400 & 5.33 \\
33 & 26 & 240 & 5400 & 3.33 \\
33 & 32 & 384 & 5400 & 5.33 \\
\hline
\end{tabular}

